\title{
A placebo-controlled study of sildenafil effects on cognition in schizophrenia
}

\author{
Donald C. Goff • Corinne Cather • \\ Oliver Freudenreich • David C. Henderson • \\ A. Eden Evins • Melissa A. Culhane • Jared P. Walsh
}

Received: 9 June 2008 / Accepted: 28 July 2008 / Published online: 21 August 2008

(C) The Author(s) 2008. This article is published with open access at Springerlink.com

\begin{abstract}
Background Phosphodiesterase 5 (PDE5) inhibitors increase cyclic guanosine monophosphate (cGMP) concentrations in the intracellular pathway activated by $N$-methyl-D-aspartic acid receptors which is believed to mediate long-term potentiation and memory consolidation. The PDE5 inhibitor sildenafil has been shown to enhance memory in animal models. In addition, neuronal nitric oxide synthase, another component of the NMDA/nitric oxide/cGMP intracellular pathway, has been reported to be dysregulated in schizophrenia patients.

Materials and methods Seventeen adult schizophrenia outpatients treated with a stable dose of antipsychotic received a single oral dose of placebo, sildenafil $50 \mathrm{mg}$, and sildenafil $100 \mathrm{mg}$ in random order with a 48-h interval between administrations. Psychiatric symptom ratings and a cognitive battery were performed at baseline and 1 hour following each administration of the study drug. In addition, memory consolidation was examined by testing recall 48 $\mathrm{h}$ later, prior to the next administration of the study drug. Results Fifteen subjects completed all three treatment conditions. One subject developed irritability and required hospitalization 2 days after receiving sildenafil $100 \mathrm{mg}$. Neither dose of sildenafil significantly affected cognitive performance or symptom ratings compared to the placebo. Conclusion Despite evidence for cognitive-enhancing effects of sildenafil in animal models, the strategy for
\end{abstract}

This study was funded by NIMH 2 K24 MH002025-06 (D. Goff).

D. C. Goff $(\bowtie) \cdot$ C. Cather • O. Freudenreich • D. C. Henderson •

A. E. Evins $\cdot$ M. A. Culhane $\cdot$ J. P. Walsh

Department of Psychiatry, MGH Schizophrenia Program,

Freedom Trail Clinic, Massachusetts General Hospital,

Harvard Medical School,

25 Staniford St., 2nd Floor,

Boston, MA 02114, USA

e-mail: goff@psych.mgh.harvard.edu treating putative NMDA receptor-mediated memory deficits in schizophrenia with sildenafil 50 and $100 \mathrm{mg}$ was not successful. It is possible that the doses used in this study were not optimal or that repeated dosing may be necessary to achieve therapeutic effects. Agents under development that inhibit other subtypes of PDE remain promising for schizophrenia and dementia.

Keywords Schizophrenia $\cdot$ Cognition $\cdot$ Memory $\cdot$ NMDA

\section{Introduction}

Hypoactivity of $N$-methyl-D-aspartate (NMDA) receptors has been identified as a possible mechanism underlying pathological symptoms and cognitive deficits in schizophrenia (Goff and Coyle 2001). Agents that enhance NMDA activity have produced mixed results in schizophrenia, with improvement of negative symptoms in some but not all trials (Buchanan et al. 2007; Tuominen et al. 2005) and largely negative effects on measures of learning and memory (Buchanan et al. 2007; Goff et al. 1999, 2005). Animal studies have demonstrated that tolerance rapidly develops for the cognitive-enhancing effects of the glycine site partial agonist, D-cycloserine, following repeated dosing (Parnas et al. 2005; Quartermain et al. 1994), possibly reflecting the trafficking of NMDA receptors from cell membrane to the intracellular compartment in response to increased activity at the glycine site (Nong et al. 2003).

Targeting pharmacological treatments at points "downstream" from the NMDA receptor, at the level of intracellular biochemical pathways, represents an alternative strategy to avoid the development of tolerance. Activation of NMDA receptors results in calcium influx into the cell, which binds to calmodulin and activates 
neuronal nitric oxide (NO) synthase (NOS), thereby increasing intracellular NO concentrations. NO activates guanylyl cyclase, which increases cyclic guanine monphosphate (cGMP; Fig. 1). This "NMDA-NO-cGMP intracellular pathway" is believed to mediate long-term potentiation and memory consolidation (Erceg et al. 2005; Prickaerts et al. 2002a; Yamada et al. 1996). Phosphodiesterase 5 (PDE5) inhibitors act to increase cGMP without directly affecting NMDA receptors. Targeting PDE5 to increase cGMP might selectively correct deficits resulting from NMDA receptor hypofunction without the development of tachyphylaxis.

Three PDE5 inhibitors are currently approved for the treatment of erectile dysfunction (sildenafil, tadalafil, and vardenafil; Rosen and Kostis 2003). These agents readily cross the blood-brain barrier, are very well tolerated, and recently have been found to have cognitive-enhancing and neuroprotective effects in rodents (Prickaerts et al. 2004; Zhang et al. 2002). PDE5 has been identified in rat brain, including the cortex and hippocampus (van Staveren et al. 2005; Van Staveren et al. 2003), and subchronic administration of sildenafil has been demonstrated to increase cortical cGMP levels (Prickaerts et al. 2002b; Zhang et al. 2002).
Intrahippocampal administration of an inhibitor of guanylate cyclase (to selectively lower cGMP concentrations) impaired learning of inhibitory avoidance in rats (Bernabeu et al. 1996), whereas administration of an analog of cGMP facilitated memory consolidation (Bernabeu et al. 1997). Sildenafil 3 and $10 \mathrm{mg} / \mathrm{kg}$. significantly improved retention at $24 \mathrm{~h}$ of an object recognition task in rats (Prickaerts et al. 2002b), and sildenafil $3 \mathrm{mg} / \mathrm{kg}$ improved retention at $48 \mathrm{~h}$ of a passive avoidance task utilizing an aversive stimulus (Baratti and Boccia 1999). Sildenafil 2, 4, and $8 \mathrm{mg} / \mathrm{kg}$ also dose-dependently improved acquisition of maze learning in mice (Singh and Parle 2003). Sildenafil reversed cognitive deficits in rats produced by electroconvulsive therapy (Patil et al. 2006), diabetes (Patil et al. 2006), anticholinergics (Devan et al. 2004), hyperammonemia (Erceg et al. 2005), and NOS inhibitors (Devan et al. 2006, 2007). Memory enhancement occurred when sildenafil was administered before training or up to $3 \mathrm{~h}$ post-training; administration immediately after training required the lowest dose, suggesting a primary effect on early memory consolidation rather than acquisition (Prickaerts et al. 2004, 2005). In a placebocontrolled trial in healthy young men, sildenafil $100 \mathrm{mg}$

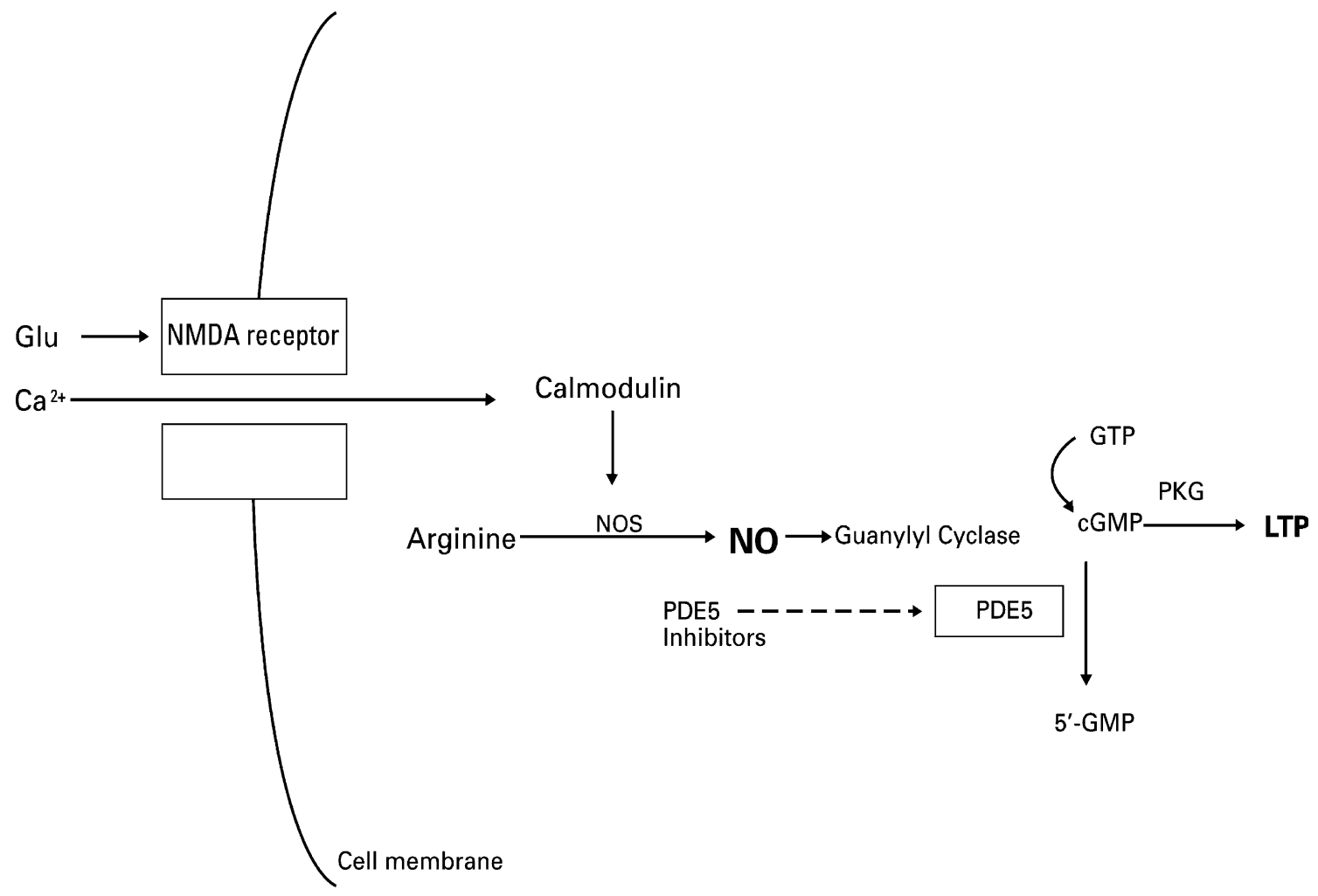

Fig. 1 Phosphodiesterase 5 (PDE5) inhibitors are believed to enhance memory and learning via facilitation of long-term potentiation (LTP) mediated by the "glutamate-nitric oxide-cyclic GMP intracellular pathway." Glutamate binding to the $N$-methyl-D-aspartate (NMDA) receptor results in calcium $\left(\mathrm{Ca}^{2+}\right)$ influx, which binds to calmodulin and activates nitric oxide synthase (NOS). NOS catalyzes the production of nitric oxide $(\mathrm{NO})$ from arginine; NO activates guanylyl cyclase, which increases production of cyclic guanosine monophosphate $(G M P)$ from guanosine triphosphate $(G T P)$. Cyclic GMP mediates LTP and activates protein kinases $(P K)$, which are believed to mediate memory consolidation via phosphorylation and protein formation. PDE5 inhibitors block the conversion of cGMP to 5'GMP; by elevating cGMP levels, LTP is facilitated 
significantly affected patterns of event-related potentials consistent with enhanced ability to focus attention and to select relevant target stimuli, although actual performance did not significantly improve (Schultheiss et al. 2001). Sildenafil was safe and effective when administered to male schizophrenia patients for erectile dysfunction in two studies (Aviv et al. 2004; Gopalakrishnan et al. 2006).

We conducted a double-blind, placebo-controlled, randomorder, single-dose crossover trial of sildenafil 50 and $100 \mathrm{mg}$ added to stable antipsychotic treatment in schizophrenia patients to assess whether this PDE5 inhibitor improves cognitive functioning and clinical symptoms.

\section{Materials and methods}

Subjects were adult outpatients with schizophrenia recruited from a community mental health center and were clinically stable without a medication change for at least 4 weeks. Subjects had to be English speaking, be medically stable without cardiac disease, and free of substance abuse or dependence for at least 3 months. Patients were excluded if they were currently taking drugs that inhibit or induce hepatic cytochrome P450 3A4, nitrates, alpha blockers, or PDE5 inhibitors. Subjects could not be pregnant or have a history of priapism or inappropriate sexual behavior.

After providing written informed consent, patients met with a research psychiatrist to verify the diagnosis of schizophrenia by Diagnostic and Statistical Manual of Mental Disorders IV criteria and to review the medical history. A physical examination and vital signs were performed, and an electrocardiogram was obtained. Women of reproductive age were given a pregnancy test and counseled regarding use of appropriate birth control methods.

After the diagnosis had been confirmed and the patient had been medically cleared by the research psychiatrist, patients were scheduled for three sessions separated by 2 days. The order of study drug (sildenafil $50 \mathrm{mg}, 100 \mathrm{mg}$, or placebo) was randomly assigned in a 1:1:1 ratio. Placebo and sildenafil were administered in identical-appearing capsules. Subjects continued to take all psychiatric medications without change during the course of the study. At baseline, the brief psychiatric rating scale (BPRS) was completed, and the cognitive battery was administered. In order to test memory consolidation, subjects returned 2 days later and were tested for a 48-h delayed recall of the Hopkins verbal learning test (HVLT) and logical memory test (LMT) that had been administered as part of the cognitive battery 2 days earlier. After blood pressure and pulse (sitting and standing) were measured, subjects were administered a single oral dose of the study drug. Starting $1 \mathrm{~h}$ after ingestion of the study drug, blood pressure, pulse, and self-reported side effects were recorded.
The BPRS and cognitive battery were then repeated. Blood pressure and pulse were recorded again $2 \mathrm{~h}$ after administration of the study drug. Subjects completed three identical postbaseline sessions and returned $48 \mathrm{~h}$ after each session for testing of delayed recall.

The cognitive battery assessed five cognitive domains and included the following tests: the HVLT (Benedict et al. 1998) using counterbalanced word lists to assess verbal learning, Letter-Number Sequencing (Wechsler Adult Intelligence Scale [WAIS]-III, The Psychological Corporation) and Digit Symbol (WAIS-III, The Psychological Corporation) to assess processing speed, category fluency to assess semantic fluency (Benton and Hamsher 1978), the continuous performance test - identical pairs to assess attention and vigilance, and Spatial Span (Wechsler Memory Scale III) to assess spatial memory. A summary score was derived for each test using the standardized $z$ score for the single item or mean for that test rectified so that a positive change in $z$ score represents improved performance. A composite cognitive score was calculated from the mean of these five $z$ scores. In addition, to assess memory consolidation, recall was tested after a 48$\mathrm{h}$ delay following administration of the HVLT to test verbal memory and the LMT (story A) from the Revised Wechsler Memory Scale (Wechsler 1997) to test verbal thematic recall.

\section{Statistical analysis}

The analysis was based on intent-to-treat and included all 17 randomized subjects. Differences in baseline and demographic variables were assessed using Student's $t$ test and Chi-square or Fisher's exact test. The primary outcome measure was change in composite cognitive score from baseline. Secondary outcome measures included change from baseline in each of the five cognitive domains, BPRS total, BPRS negative symptom subscale, BPRS depression item, and 48-h delayed performance on the HVLT and LMT. For these variables, analysis of covariance were performed to determine differences between placebo, sildenafil 50 and $100 \mathrm{mg}$, controlling for order (PROC GLM). All analyses were performed using SAS. An alpha of 0.05 was used to determine significance, and because of the exploratory nature of this study, a correction was not made for multiple comparisons.

\section{Results}

Eighteen patients were enrolled, 17 were randomized, and 15 completed all three treatment conditions. One subject dropped out after the first treatment session (placebo), and one was dropped from study 2 days after the first treatment session (sildenafil $100 \mathrm{mg}$ ) due to irritability; this patient was subsequently hospitalized. The mean age of completers 
was 49.7 years $(\mathrm{SD}=0.6)$. Eight subjects $(47 \%)$ were male. Twelve of the 17 subjects $(71 \%)$ were Caucasian, four subjects (24\%) were African-American, and one subject $(6 \%)$ was Hispanic. Five subjects were treated with olanzapine, two with clozapine, two with aripiprazole, two with conventional antipsychotics, two with risperidone, one with quetiapine, and three with combination (quetiapine and fluphenazine, olanzapine and ziprasidone, and perphenazine and ziprasidone).

There was no significant main effect of study medication on change in composite cognitive score from baseline. Additionally, a main effect of study medication was not found for any of the secondary outcome measures. Effect sizes of study drug for cognitive domains ranged from 0.07 (small) to 0.61 (large), and in each comparison, performance improved more (or worsened less) with placebo compared to sildenafil. Effect sizes for the Positive and Negative Syndrome Scale (PANSS) total and PANSS subscale scores were all small $(0.00-0.21)$ and also favored placebo.

\section{Side effects}

Sildenafil was generally well tolerated, although one dropout due to irritability occurred following administration of sildenafil $100 \mathrm{mg}$. One subject reported moderate sedation $1 \mathrm{~h}$ after the sildenafil $100-\mathrm{mg}$ dose. Two subjects exhibited drops in diastolic blood pressure of 7 and

Table 1 Mean change scores from baseline to poststudy drug administration

\begin{tabular}{|c|c|c|c|c|c|c|c|}
\hline & Placebo & Sildenafil $50 \mathrm{mg}$ & ES & Sildenafil $100 \mathrm{mg}$ & ES & $F$ value & $p$ value \\
\hline \multicolumn{8}{|l|}{ Symptoms } \\
\hline \multicolumn{8}{|l|}{$\mathrm{BPRS}^{\mathrm{a}}$} \\
\hline Positive symptom total & $0.06 \pm 0.25$ & $0.40 \pm 1.30$ & 0.21 & $0.06 \pm 0.25$ & 0.00 & 0.01 & 0.99 \\
\hline Negative symptom total & $-0.15 \pm 0.54$ & $-0.16 \pm 0.67$ & 0.02 & $-0.08 \pm 0.71$ & 0.14 & 0.08 & 0.93 \\
\hline Depression item & $-0.06 \pm 0.25$ & $0.00 \pm 0.00$ & 0.06 & $0.00 \pm 0.00$ & 0.06 & 0.04 & 0.96 \\
\hline Total & $-0.19 \pm 1.22$ & $-0.20 \pm 0.56$ & 0.00 & $-0.06 \pm 0.57$ & 0.03 & 0.30 & 0.74 \\
\hline \multicolumn{8}{|l|}{ Cognitive tests ${ }^{\mathrm{b}}$} \\
\hline \multicolumn{8}{|l|}{ HVLT } \\
\hline Total recall & $-0.50 \pm 5.05$ & $-0.87 \pm 4.00$ & 0.08 & $-1.50 \pm 4.58$ & 0.22 & 0.19 & 0.83 \\
\hline Delayed (48 h) recall & $-1.53 \pm 2.45$ & $-1.27 \pm 1.98$ & 0.11 & $-2.07 \pm 2.55$ & 0.23 & 0.44 & 0.64 \\
\hline \multicolumn{8}{|l|}{ Letter number } \\
\hline Without reordering & $0.56 \pm 1.86$ & $0.47 \pm 1.19$ & 0.05 & $0.44 \pm 1.75$ & 0.07 & 0.02 & 0.98 \\
\hline With reordering & $0.13 \pm 1.54$ & $-0.40 \pm 1.68$ & $0.33^{\mathrm{c}}$ & $0.00 \pm 1.55$ & 0.08 & 0.45 & 0.64 \\
\hline Digit symbol total & $7.19 \pm 8.42$ & $3.20 \pm 7.05$ & $0.49^{\mathrm{c}}$ & $5.63 \pm 9.06$ & 0.19 & 0.93 & 0.40 \\
\hline Animals: total & $3.69 \pm 3.65$ & $2.60 \pm 3.27$ & $0.31^{\mathrm{c}}$ & $3.00 \pm 3.46$ & 0.20 & 0.39 & 0.68 \\
\hline \multicolumn{8}{|l|}{ CPT-IP } \\
\hline $2 \mathrm{~d}^{\prime}$ & $0.24 \pm 0.69$ & $0.05 \pm 0.86$ & 0.26 & $0.02 \pm 0.62$ & $0.30^{\mathrm{c}}$ & 0.38 & 0.68 \\
\hline $3 \mathrm{~d}^{\prime}$ & $0.25 \pm 0.83$ & $0.34 \pm 0.92$ & 0.11 & $0.26 \pm 0.81$ & 0.01 & 0.04 & 0.96 \\
\hline $4 \mathrm{~d}^{\prime}$ & $0.50 \pm 0.57$ & $0.18 \pm 0.67$ & $0.54^{\mathrm{c}}$ & $0.28 \pm 0.53$ & $0.37^{\mathrm{c}}$ & 1.11 & 0.34 \\
\hline \multicolumn{8}{|l|}{ Spatial span } \\
\hline Forward & $-0.06 \pm 1.69$ & $-0.14 \pm 1.23$ & 0.05 & $-0.38 \pm 1.63$ & 0.21 & 0.17 & 0.84 \\
\hline Reverse & $0.94 \pm 1.65$ & $0.57 \pm 1.74$ & 0.22 & $0.63 \pm 1.63$ & 0.19 & 0.22 & 0.80 \\
\hline \multicolumn{8}{|l|}{ Logical memory-thematic } \\
\hline Immediate & $0.94 \pm 1.12$ & $0.80 \pm 1.78$ & 0.10 & $0.81 \pm 1.33$ & 0.09 & 0.05 & 0.95 \\
\hline Delayed (48 h) & $2.27 \pm 1.71$ & $1.80 \pm 1.90$ & 0.29 & $2.20 \pm 1.61$ & 0.04 & 0.36 & 0.70 \\
\hline \multicolumn{8}{|l|}{ Logical memory-unit } \\
\hline Immediate & $3.56 \pm 2.85$ & $2.87 \pm 3.83$ & 0.22 & $3.38 \pm 3.26$ & 0.06 & 0.21 & 0.81 \\
\hline Delayed (48 h) & $6.13 \pm 4.60$ & $5.80 \pm 5.62$ & 0.07 & $6.33 \pm 5.34$ & 0.04 & 0.05 & 0.95 \\
\hline \multicolumn{8}{|l|}{ Cognitive domains ( $z$ scores $)^{\mathrm{b}}$} \\
\hline Verbal memory & $-0.01 \pm 1.06$ & $-0.08 \pm 0.84$ & 0.07 & $-0.22 \pm 0.97$ & 0.22 & 0.19 & 0.83 \\
\hline Working memory & $-0.05 \pm 0.30$ & $-0.23 \pm 0.23$ & $0.61^{\mathrm{d}}$ & $-0.12 \pm 0.34$ & 0.24 & 1.47 & 0.24 \\
\hline Semantic fluency & $0.02 \pm 0.61$ & $-0.18 \pm 0.58$ & $0.34^{\mathrm{c}}$ & $-0.10 \pm 0.61$ & 0.20 & 0.46 & 0.63 \\
\hline Attention & $0.06 \pm 0.43$ & $-0.12 \pm 0.49$ & $0.38^{\mathrm{c}}$ & $-0.12 \pm 0.51$ & $0.38^{\mathrm{c}}$ & 0.71 & 0.50 \\
\hline Spatial memory & $-0.01 \pm 0.68$ & $-0.11 \pm 0.46$ & 0.17 & $-0.15 \pm 0.53$ & 0.24 & 0.25 & 0.78 \\
\hline Cognitive composite ( $z$ scores) & $0.00 \pm 0.32$ & $-0.13 \pm 0.33$ & $0.40^{\mathrm{c}}$ & $-0.14 \pm 0.33$ & $0.43^{\mathrm{c}}$ & 0.95 & 0.39 \\
\hline
\end{tabular}

${ }^{a}$ Positive change from baseline reflects worsening/negative change from baseline reflects improvement in measure

${ }^{\mathrm{b}}$ Positive change from baseline reflects improvement/negative change from baseline reflects worsening in measure

${ }^{\mathrm{c}}$ Medium effect size

${ }^{\mathrm{d}}$ Large effect size 
$14 \mathrm{mmHg}$ after sildenafil $100 \mathrm{mg}$; in both cases, the systolic blood pressure did not drop, and the subject remained asymptomatic. Reports of dizziness were not more common with sildenafil compared to placebo, and no headaches or visual disturbances were reported (Table 1).

\section{Discussion}

Our hypothesis, that sildenafil would improve cognition when added to antipsychotics in patients with schizophrenia, was not supported. The explanation for this negative finding is uncertain. It is possible that the potential effect is too small to detect in a sample of this size. It is also possible that both doses of sildenafil administered in this study were outside an effective dose range. Studies in rats have identified an inverted U-shaped dose-response relationship with an optimal dose of $1-10 \mathrm{mg} / \mathrm{kg}$. In an object recognition task in rats, sildenafil improved memory when administered at a dose of $3 \mathrm{mg} / \mathrm{kg}$ immediately after training, whereas a dose of $10 \mathrm{mg} / \mathrm{kg}$ was required when administered $30 \mathrm{~min}$ prior to training. The increase in minimum effective dose was attributed to the rapid metabolism of sildenafil (half-life of $0.4 \mathrm{~h}$ ) necessitating a higher dose to achieve adequate brain concentrations during the period of cGMP-dependent memory consolidation (Prickaerts et al. 2004). The half-life of sildenafil in humans is $4 \mathrm{~h}$, suggesting that administration $1 \mathrm{~h}$ prior to cognitive testing should not be complicated by the rapid clearance observed in rats (Boolell et al. 1996). Because sildenafil readily crosses the blood-brain barrier, the doses administered in this study would be expected to substantially inhibit brain PDE5. It is possible that repeated dosing may be required to produce cognitive or behavioral effects. In animal studies, cognitive effects have been demonstrated with both single and repeated dosing. Daily dosing with sildenafil has not been studied in schizophrenia, although this approach has been utilized successfully in the treatment of pulmonary hypertension (Chockalingam et al. 2005).

Sildenafil was generally well tolerated, although one subject experienced irritability following sildenafil $100 \mathrm{mg}$. While it is unclear whether this dysphoric response resulted from study drug, rare reports of central nervous system adverse effects have been reported, including aggression and amnesia (Milman and Arnold 2002). In addition, increased aggression was observed in mice 1 week after discontinuation of a 4-week regimen of high-dose sildenafil administered three times weekly (Hotchkiss et al. 2005). However, no worsening of psychiatric symptom ratings was observed in a 6-week open trial of sildenafil $25-75 \mathrm{mg}$ administered as needed to 12 schizophrenia patients with erectile dysfunction (Aviv et al. 2004).

A large literature has implicated dysregulation of neuronal NOS in schizophrenia (Bernstein et al. 2005).
Evidence suggesting abnormalities in this intermediate step of the NMDA/NO/cGMP pathway include linkage of the carboxyl-terminal PDZ-ligand of nNos (CAPON) to schizophrenia (Eastwood 2005), altered concentrations of NO and NO metabolites in blood and cerebrospinal fluid, and, in postmortem brain, abnormalities in the cortical distribution of neuronal NOS (nNOS)-expressing neurons (Akbarian et al. 1993), nNOS ribonucleic acid expression, and nNOS activity (Bernstein et al. 2005). However, the complexity of findings makes it difficult to predict whether dysregulation of $\mathrm{NO}$ is primarily in the direction of an increase or decrease. In addition, haloperidol and chlorpromazine but not secondgeneration antipsychotics, decrease nNOS activity in rats (Nel and Harvey 2003; Tarazi et al. 2002). Deutsch et al. (1997) reported an improvement in psychopathology ratings with the NOS inhibitor, methylene blue, in a pilot study of eight antipsychotic-refractory schizophrenia patients.

Whereas evidence for dysregulation of nNOS in schizophrenia supports pharmacological targeting of the NMDA/ NO/cGMP pathway, it is possible that an underlying impairment of function in this pathway could result in reduced or absent cognitive enhancement with PDE5 inhibition. PDE5 inhibition amplifies the signal generated by NMDA receptor activation and NO release; cGMP levels will not increase if this pathway is not intact. Studies in healthy, medication-free subjects are needed to assess whether the encouraging findings of cognitive enhancement in animal models can be translated to humans. The one published study of sildenafil in healthy subjects produced ambiguous results; electrophysiologic measures of concentration improved, whereas performance did not (Schultheiss et al. 2001). In addition, inhibitors of other subtypes of PDE may be more effective in producing cognitive effects in humans. PDE4 inhibitors are currently being developed for cognitive disorders, and PDE10 inhibitors are under study for the treatment of schizophrenia (Bender and Beavo 2006).

\section{Conclusion}

Despite an animal literature demonstrating cognitiveenhancing effects of sildenafil and a rationale for sildenafil as a strategy for facilitating NMDA receptor-mediated effects on memory by targeting intracellular pathways downstream from NMDA receptors, we did not detect effects of a single dose of sildenafil 50 and $100 \mathrm{mg}$ on a traditional cognitive battery, nor did we find evidence for improved memory consolidation when recall was tested after $48 \mathrm{~h}$. Symptoms of schizophrenia also did not improve. It is possible that the doses used in this study were not optimal, that repeated dosing may be necessary to achieve therapeutic effects, or that PDE5 inhibition is not a viable strategy in medicated schizophrenia patients. Additional 
studies of alternative dosing strategies in healthy subjects may provide some clarification. Agents under development that inhibit other subtypes of PDE remain promising.

Open Access This article is distributed under the terms of the Creative Commons Attribution Noncommercial License which permits any noncommercial use, distribution, and reproduction in any medium, provided the original author(s) and source are credited.

\section{References}

Akbarian S, Bunney WJ, Potkin S, Wigal S, Hagman J, Sandman C et al (1993) Altered distribution of nicotinamide-adenine dinucleotide phosphate-diaphorase cells in frontal lobe of schizophrenics implies disturbances of cortical development. Arch Gen Psychiatry 50:169-177

Aviv A, Shelef A, Weizman A (2004) An open-label trial of sildenafil addition in risperidone-treated male schizophrenia patients with erectile dysfunction. J Clin Psychiatry 65:97-103

Baratti CM, Boccia MM (1999) Effects of sildenafil on long-term retention of an inhibitory avoidance response in mice. Behav Pharmacol 10:731-737

Bender AT, Beavo JA (2006) Cyclic nucleotide phosphodiesterases: molecular regulation to clinical use. Pharmacol Rev 58:488-520

Benedict RHB, Schretlen D, Groninger L, Brandt J (1998) Hopkins verbal learning test-revised: normative data and analysis of interform and test-retest reliability. Clin Neuropsychologist 12:43-55

Benton A, Hamsher K (1978) Multilingual aphasia examination (manual revised). University of Iowa, Iowa City

Bernabeu R, Schmitz P, Faillace MP, Izquierdo I, Medina JH (1996) Hippocampal cGMP and cAMP are differentially involved in memory processing of inhibitory avoidance learning. Neuroreport 7:585-588

Bernabeu R, Schroder N, Quevedo J, Cammarota M, Izquierdo I, Medina JH (1997) Further evidence for the involvement of a hippocampal cGMP/cGMP-dependent protein kinase cascade in memory consolidation. Neuroreport 8:2221-2224

Bernstein HG, Bogerts B, Keilhoff G (2005) The many faces of nitric oxide in schizophrenia. A review. Schizophr Res 78:69-86

Boolell M, Allen MJ, Ballard SA, Gepi-Attee S, Muirhead GJ, Naylor AM et al (1996) Sildenafil: an orally active type 5 cyclic GMPspecific phosphodiesterase inhibitor for the treatment of penile erectile dysfunction. Int J Impot Res 8:47-52

Buchanan RW, Javitt DC, Marder SR, Schooler NR, Gold JM, McMahon RP et al (2007) The Cognitive and Negative Symptoms in Schizophrenia Trial (CONSIST): the efficacy of glutamatergic agents for negative symptoms and cognitive impairments. Am J Psychiatry 164:1593-1602

Chockalingam A, Gnanavelu G, Venkatesan S, Elangovan S, Jagannathan V, Subramaniam T et al (2005) Efficacy and optimal dose of sildenafil in primary pulmonary hypertension. Int $\mathrm{J}$ Cardiol 99:91-95

Deutsch SI, Rosse RB, Schwartz BL, Fay-McCarthy M, Rosenberg PB, Fearing K (1997) Methylene blue adjuvant therapy of schizophrenia. Clin Neuropharmacol 20:357-363

Devan BD, Sierra-Mercado D Jr, Jimenez M, Bowker JL, Duffy KB, Spangler EL et al (2004) Phosphodiesterase inhibition by sildenafil citrate attenuates the learning impairment induced by blockade of cholinergic muscarinic receptors in rats. Pharmacol Biochem Behav 79:691-699

Devan BD, Bowker JL, Duffy KB, Bharati IS, Jimenez M, SierraMercado D Jr et al (2006) Phosphodiesterase inhibition by sildenafil citrate attenuates a maze learning impairment in rats induced by nitric oxide synthase inhibition. Psychopharmacology (Berl) 183:439-445

Devan BD, Pistell PJ, Daffin LW Jr, Nelson CM, Duffy KB, Bowker JL et al (2007) Sildenafil citrate attenuates a complex maze impairment induced by intracerebroventricular infusion of the NOS inhibitor Nomega-nitro-L-arginine methyl ester. Eur J Pharmacol 563:134-140

Eastwood SL (2005) Does the CAPON gene confer susceptibility to schizophrenia? PLoS Med 2:e348

Erceg S, Monfort P, Hernandez-Viadel M, Rodrigo R, Montoliu C, Felipo V (2005) Oral administration of sildenafil restores learning ability in rats with hyperammonemia and with portacaval shunts. Hepatology 41:299-306

Goff DC, Coyle JT (2001) The emerging role of glutamate in the pathophysiology and treatment of schizophrenia. Am J Psychiatry 158:1367-1377

Goff D, Tsai G, Levitt J, Amico E, Manoach D, Schoenfeld D et al (1999) A placebo-controlled trial of D-cycloserine added to conventional neuroleptics in patients with schizophrenia. Arch Gen Psychiatry 56:21-27

Goff DC, Herz L, Posever T, Shih V, Tsai G, Henderson DC et al (2005) A six-month, placebo-controlled trial of D-cycloserine coadministered with conventional antipsychotics in schizophrenia patients. Psychopharmacology (Berl) 179:144-150

Gopalakrishnan R, Jacob KS, Kuruvilla A, Vasantharaj B, John JK (2006) Sildenafil in the treatment of antipsychotic-induced erectile dysfunction: a randomized, double-blind, placebocontrolled, flexible-dose, two-way crossover trial. Am J Psychiatry 163:494-499

Hotchkiss AK, Pyter LM, Gatien ML, Wen JC, Milman HA, Nelson RJ (2005) Aggressive behavior increases after termination of chronic sildenafil treatment in mice. Physiol Behav 83:683-688

Milman HA, Arnold SB (2002) Neurologic, psychological, and aggressive disturbances with sildenafil. Ann Pharmacother 36:1129-1134

Nel A, Harvey BH (2003) Haloperidol-induced dyskinesia is associated with striatal NO synthase suppression: reversal with olanzapine. Behav Pharmacol 14:251-255

Nong Y, Huang YQ, Ju W, Kalia LV, Ahmadian G, Wang YT et al (2003) Glycine binding primes NMDA receptor internalization. Nature 422:302-307

Parnas AS, Weber M, Richardson R (2005) Effects of multiple exposures to D-cycloserine on extinction of conditioned fear in rats. Neurobiol Learn Mem 83:224-231

Patil CS, Singh VP, Kulkarni SK (2006) Modulatory effect of sildenafil in diabetes and electroconvulsive shock-induced cognitive dysfunction in rats. Pharmacol Rep 58:373-380

Prickaerts J, de Vente J, Honig W, Steinbusch HW, Blokland A (2002a) cGMP, but not cAMP, in rat hippocampus is involved in early stages of object memory consolidation. Eur J Pharmacol 436:83-87

Prickaerts J, van Staveren WC, Sik A, Markerink-van Ittersum M, Niewohner U, van der Staay FJ et al (2002b) Effects of two selective phosphodiesterase type 5 inhibitors, sildenafil and vardenafil, on object recognition memory and hippocampal cyclic GMP levels in the rat. Neuroscience 113:351-361

Prickaerts J, Sik A, van Staveren WC, Koopmans G, Steinbusch HW, van der Staay FJ et al (2004) Phosphodiesterase type 5 inhibition improves early memory consolidation of object information. Neurochem Int 45:915-928

Prickaerts J, Sik A, van der Staay FJ, de Vente J, Blokland A (2005) Dissociable effects of acetylcholinesterase inhibitors and phosphodiesterase type 5 inhibitors on object recognition memory: acquisition versus consolidation. Psychopharmacology (Berl) 177:381-390 
Quartermain D, Mower J, Rafferty MF, Herting RL, Lanthorn TH (1994) Acute but not chronic activation of the NMDA-coupled glycine receptor with d-cycloserine facilitates learning and retention. Eur J Pharm 257:7-12

Rosen RC, Kostis JB (2003) Overview of phosphodiesterase 5 inhibition in erectile dysfunction. Am J Cardiol 92:9M-18M

Schultheiss D, Muller SV, Nager W, Stief CG, Schlote N, Jonas U et al (2001) Central effects of sildenafil (Viagra) on auditory selective attention and verbal recognition memory in humans: a study with event-related brain potentials. World J Urol 19:46-50

Singh N, Parle M (2003) Sildenafil improves acquisition and retention of memory in mice. Indian J Physiol Pharmacol 47:318-324

Tarazi FI, Zhang K, Baldessarini RJ (2002) Long-term effects of newer antipsychotic drugs on neuronal nitric oxide synthase in rat brain. Nitric Oxide 7:297-300

Tuominen HJ, Tiihonen J, Wahlbeck K (2005) Glutamatergic drugs for schizophrenia: a systematic review and meta-analysis. Schizophr Res 72:225-234
Van Staveren WC, Steinbusch HW, Markerink-Van Ittersum M, Repaske DR, Goy MF, Kotera J et al (2003) mRNA expression patterns of the cGMP-hydrolyzing phosphodiesterases types 2, 5, and 9 during development of the rat brain. J Comp Neurol 467:566-580

van Staveren WC, Markerink-van Ittersum M, Steinbusch HW, Behrends S, de Vente J (2005) Localization and characterization of cGMP-immunoreactive structures in rat brain slices after NOdependent and NO-independent stimulation of soluble guanylyl cyclase. Brain Res 1036:77-89

Wechsler D (1997) Wechsler memory scale, 3rd edn. Psychological, San Antonio, TX

Yamada K, Hiramatsu M, Noda Y, Mamiya T, Murai M, Kameyama T et al (1996) Role of nitric oxide and cyclic GMP in the dizocilpine-induced impairment of spontaneous alternation behavior in mice. Neuroscience 74:365-374

Zhang R, Wang Y, Zhang L, Zhang Z, Tsang W, Lu M et al (2002) Sildenafil (Viagra) induces neurogenesis and promotes functional recovery after stroke in rats. Stroke 33:2675-2680 